\title{
Does Television Exposure Affect Emerging Adults' Attitudes and Assumptions About Sexual Relationships? Correlational and Experimental Confirmation
}

\author{
L. Monique Ward ${ }^{1}$
}

Received November 27, 2000; accepted August 3, 2001

\begin{abstract}
Because concern is frequently raised that TV's abundant yet stereotypical portrayals of sexual relationships may mislead young viewers, this study examined the effects of both regular viewing habits and experimental exposure on students' conceptions about sexual relationships. A multiethnic sample of 259 undergraduates aged 18-22 was assigned to view a set of clips depicting either 1 of 3 sexual stereotypes or neutral, nonsexual content. Participants then completed measures assessing their attitudes about sexual roles and relationships, their assumptions about the sexual experiences of their peers, and their regular viewing habits. Both correlational and experimental connections emerged between TV viewing and students' sexual attitudes and assumptions. More frequent and more involved viewing were repeatedly associated with students' support of the sexual stereotypes surveyed. Similarly, women exposed to clips representing a particular sexual stereotype were more likely to endorse that notion than were women exposed to nonsexual content. Finally, both experimental exposure and aspects of regular viewing significantly predicted students' sexual attitudes and assumptions, even with demographics and previous sexual experiences controlled.
\end{abstract}

KEY WORDS: television; media; sexuality.

\section{INTRODUCTION}

A central developmental task throughout late adolescence and emergent adulthood (Arnett, 2000) is establishing sexual relationships. From first loves to Spring Break "hook-ups," youth must learn to negotiate the dynamics of the dating arena, making a number of complex decisions concerning the selection of partners, initiation of sexual activities, and protection against pregnancy

An earlier version of this paper was presented at the 2000 Biennial Meeting of the Society for Research on Adolescence, Chicago, Illinois. The author thanks Maya Gordon, Ben Gorvine, and Rocio Rivadeneyra for their assistance with various aspects of this project, as well as Dr Jane Brown and several anonymous reviewers for their insightful comments. ${ }^{1}$ Assistant Professor, Psychology Department, University of Michigan, Ann Arbor, Michigan. Received a PhD in Psychology (Developmental) from the University of California, Los Angeles, and conducts research exploring contributions of parents, peers, and the media to gender and sexual socialization. To whom correspondence should be addressed at Psychology Department, University of Michigan, 525 E. University Avenue, Ann Arbor, Michigan, 48109-1109; e-mail: ward@ umich.edu. and disease. As outlined in several theoretical models (e.g., Christopher, 2001; Fishbein and Middlestadt, 1989; Fisher, 1988), 2 factors believed to play a central role in these decision-making processes are emergent adults' attitudes and beliefs about sexual relationships and their perceptions of peer norms and behavior. These include perceptions about how sexually active their peers are, general beliefs about the dynamics of heterosexual relationships, and assumptions about the norms of masculinity and femininity. Evidence indicates several significant connections between these beliefs and later sexual decisionmaking. For example, greater acceptance of stereotypical attitudes about gender and about sexual roles is associated with less effective contraceptive use and an earlier age of sexual activity (e.g., Fox, 1977; MacCorquodale, 1984; Pleck et al., 1993). At the same time, presuming higher levels of sexual activity of one's peers is associated with having more and riskier sexual experiences oneself (e.g., Page et al., 2000; Whitaker and Miller, 2000; Winslow et al., 1992). Thus, beliefs about what is appropriate "feminine" behavior (e.g., "nice girls don't"), 
appropriate "masculine" behavior (e.g., "real men score"), and age-appropriate norms (i.e., "everyone is doing it") appear to be powerful forces shaping the sexual decisions and behaviors of emergent adults.

How do youth come to develop these gender-specific norms and these assumptions about peer sexual behavior? While personal conversations with peers are a likely contributor (e.g., Andre et al., 1989; DiOrio et al., 1999; Pistella and Bonati, 1998), it is also believed that television has assumed a prominent role in "educating" American youth about sex (Brown and Steele, 1995; Huston et al., 1998; Strasburger, 1995). From daytime soap operas to prime-time situation comedies, television presents countless verbal and visual examples of how dating, intimacy, sex, and relationships are handled. Content analyses consistently indicate that references to sexual issues are abundant on prime-time sit-coms and dramas (e.g., Sapolsky and Tabarlet, 1991; Ward, 1995), soap operas (e.g., Lowry and Towles, 1989; Olson, 1994), and music videos (e.g., Sherman and Dominick, 1986). An average of 10 instances of sexual behavior appear per hour on soaps (Greenberg and Busselle, 1996), and 29\% of the interactions on prime-time programs popular among youth contain verbal references to sexual issues (Ward, 1995). These numbers appear to be increasing, with recent reports that $65 \%$ of prime-time network programs analyzed from 1 week included talk about sexuality (Kunkel et al., 1999). Thus, television offers abundant material from which viewers can construct and validate beliefs about sexual relationships.

However, despite television's potential for educating about sexual relationships, the general conclusion is that the messages it sends about sexuality are distorted, stereotypical, and potentially harmful. Formal analyses of TV's sexual content consistently reveal that the bulk of sexual actions occur between characters who are not married to each other and include little mention of safe sex, contraception, and sexually transmitted diseases (e.g., Kunkel et al., 1996; Sapolsky and Tabarlet, 1991). In addition, depictions of courtship and sexual relationships are often stereotypical, frequently featuring sex-driven males competing with each other for females, who are viewed as sexual objects or conquests (Gow, 1995; Ward, 1995). While portrayals of healthy male-female relationships and responsible sexual decision-making are present, they may be overshadowed by more frequent and more "titillating" depictions of sex as recreational, superficial, and inconsequential. Therefore, the prevalent yet limited nature of TV's sexual portrayals has raised concern that heavy viewing of these images may lead to stereotypical or casual attitudes toward sexual relationships, distorted expectations, and irresponsible sexual decision-making.
Evidence suggests that these concerns are warranted. Although the research in this area has been sparse, correlational analyses link frequent TV viewing with more liberal sexual attitudes, assumptions, and behavior. First, greater exposure to sexually oriented genres, such as soap operas and music videos, has been related to expressing more liberal attitudes about sex (e.g., Strouse and BuerkelRothfuss, 1987; Walsh-Childers and Brown, 1993), with stronger endorsement of dysfunctional beliefs about relationships (Haferkamp, 1999), and with a greater acceptance of sexual harassment (Strouse et al., 1994). Second, greater exposure to these genres has been linked to viewers' assumptions about the prevalence of sex and of certain sexual activities frequently depicted on TV (e.g., BuerkelRothfuss and Strouse, 1993; Carveth and Alexander, 1985). For example, undergraduates who frequently view soap operas offer higher estimates of the numbers of real people who divorce or sire illegitimate children than do less frequent viewers. Finally, heavier consumption of sexually oriented genres has been linked to a greater number of sexual partners and to an earlier age of 1st intercourse (Brown and Newcomer, 1991; Strouse et al., 1995; Strouse and Buerkel-Rothfuss, 1987).

Despite these results, questions remain about the power and reach of TV's contribution to sexual socialization. First, because most existing findings are correlational, causality has not been firmly established. Indeed, many dismiss these findings as mere confirmation that viewers with liberal sexual attitudes and assumptions are drawn to programming that confirms their beliefs. Moreover, the handful of experimental studies that do exist have produced promising yet mixed results. In one study (Calfin et al., 1993), 151 White undergraduates viewed either a romantic Amy Grant video, an erotic Madonna video, or no video, and then completed an 18-item survey about their sexual attitudes. Differences emerged between these groups for 8 of the items, with the controls appearing more "liberal" for some of the items and the experimental groups appearing more "liberal" for others. Similar findings were reported by Kalof (1999) who exposed 44 White undergraduates to either a sexually stereotyped Michael Jackson music video or to a nonsexual music video. Group differences emerged for 1 of the 4 dimensions of sexual attitudes assessed, such that students in the experimental group were more likely to endorse adversarial sexual beliefs than were students in the control group. Using a larger exposure and younger sample, Greeson and Williams (1986) reported that 7 th and 10th graders who viewed 9-10 music videos were more likely to agree with the statement, "Premarital sex is okay for teens," than were students who had not had this exposure. Finally, exposure to several sexual scenes drawn from prime-time soaps and dramas 
was found to increase teens' acceptance of sexual improprieties in one study (Bryant and Rockwell, 1994), but to have no effects on their beliefs in another (Greenberg et al., 1993).

Viewing the findings as a whole, it appears as if significant group differences in attitudes can be produced by experimental exposure to sexual content, even from brief, one-time, video exposure. Results emerge among females and males, and among high school students and college students, indicating that undergraduates are neither too jaded nor too experienced to be affected. Yet the results are hardly consistent, and null results have emerged within each study nearly as often, if not more often, than experimental effects. The issue clearly has not been resolved.

A second limitation of the literature is that assessments of how TV exposure contributes to sexual socialization have focused mainly on the amounts of TV viewed, following arguments of cultivation theory (Gerbner et al., 1994). According to this perspective, television's consistent images and portrayals construct a specific portrait of reality, and as viewers watch more television, they gradually come to cultivate or adopt attitudes and expectations about the real world that coincide with this portrait. The assumption, then, is that TV has the strongest impact on the people who watch it the most. Yet I believe that viewing amounts are only 1 avenue through which TV's influence is manifested. Working from a constructivist perspective that highlights the active, sense-making role of the viewer, I argue that attention is needed on aspects of viewer participation and involvement that might also steer media impact. Indeed, evidence indicates that people who are more active and involved viewers, who identify more strongly with the portrayals, who view TV with specific purposes or motives in mind, or who attribute greater realism to the portrayals are more likely to be affected by the content viewed (Baran, 1976; Dorr, 1986; Harrison, 1997; Levy and Windahl, 1984; Perse, 1986; Potter, 1986; Rubin, 1994). Because these behaviors may or may not coexist with frequent viewing, important avenues of TV's influence may be overlooked if the sole focus is on viewing amounts.

A final limitation of the current evidence is the global conceptualization of sexual messages and attitudes. While most studies examine links between TV exposure and viewers' general attitudes about sexuality (e.g., endorsement of premarital sex), a good portion of TV's sexual content is in fact gender-specific, emphasizing different messages for women than for men about expected sexual behavior (Ward, 1995). In our society, sex is not just sex. Instead, a sexual double standard prevails in which sexual dictates, norms, attitudes, and behaviors vary greatly by gender (Oliver and Hyde, 1993; Schwartz and Rutter,
1998). The dichotomy setup is one of female passivity and responsibility and male sexual aggressiveness. Young women are expected to be sexually attractive, but not too sexually active or assertive. Their goal is to attract a man and establish a loving relationship. Male sexuality is seen as natural, urgent, and relentless (Tolman and Higgins, 1996). Young men are expected to be "players," to "sow their wild oats," and to "score" at all costs. However, while these are the messages about sexuality that dominate both in the larger culture and on television (Ward, 1995), they are not the ones typically examined in the literature. Thus, I believe it is critical to move these gender-specific notions about sexuality to the forefront of research on media and sexual socialization. A direct test is needed of whether TV exposure affects viewers' endorsement of the particular themes about sexuality that appear most frequently.

Accordingly, this study sought to expand conceptualizations of television's role as a sexual socializer in 3 specific ways. First, in examining whether media exposure shapes students' sexual attitudes and assumptions, it employs 2 methods, one correlational and the other experimental, to more fully capture the dynamics involved. With a correlational approach, it is possible to assess associations between regular viewing habits and students' conceptions of sexual relationships. With the experimental approach, inferences of causality are possible if it can be demonstrated that students randomly assigned to view specific sexual content offer stronger endorsement of the messages conveyed than students assigned to view nonsexual content. Although the real world implications of experimental results are sometimes questioned, they can be informative if perceived within the appropriate context. Indeed, the expectation was not that this one exposure would cause viewers to adopt forever these particular attitudes about sexual relationships; instead, the experimental stimulus was expected to prime existing stereotypical sexual schemas which would serve as a lens through which subsequent information and experiences would be viewed (e.g., Higgins and King, 1981; Jo and Berkowitz, 1994). Thus, following this one exposure, material conveying a stereotypical approach to sexual roles and relationships would temporarily seem more acceptable.

An additional benefit of including both methodologies is that experimental effects can be examined in light of regular viewing behavior. For experimental stimuli to have maximum real world implications, participants would need to be exposed to stimuli they would have chosen to view on their own. Indeed, if a stimulus has an effect, but participants would normally not have chosen to expose themselves to that content, the findings hold little utility. In consideration of these dynamics, potential experimental effects were examined among both infrequent viewers 
and among frequent viewers, who were more likely to be exposed to such content outside the lab.

Second, in testing how regular media exposure affects viewers, I considered the contributions of both viewing amount and viewer involvement. In keeping with previous findings, assessments of viewing amount focused on sexually oriented genres, namely prime-time comedies and dramas, soap operas, and music videos. Drawing from premises of cultivation theory, it was expected that more frequent viewing of these genres would be associated with more stereotypical attitudes about sexuality. In assessing contributions of viewer involvement, emphasis was placed on the following 3 components: level of active viewing, identification with popular characters, and viewing motivations. Following premises of several constructivist approaches (e.g., uses and gratifications theory; Rubin, 1994), it was expected that these factors would also correlate positively with students' stereotypical attitudes about sexual relationships.

Finally, the impact of media exposure was assessed on several dimensions of students' sexual beliefs, including their general views about sexual relationships, their attitudes about gender-specific sexual roles, and their assumptions about the sexual experiences of their peers. Selected for examination were the following 3 themes about sexual relationships reported to occur most frequently on prime-time programs popular among youth (Ward, 1995): (1) dating is a game or recreational sport; (2) women are sexual objects whose value is based on their physical appearance; and (3) men are sex-driven creatures who have trouble being faithful. Media exposure was expected to be associated both with stronger endorsement of these sexual stereotypes and with higher expectations of peer sexual activity (i.e., a stronger sense that "everyone is doing it"). Attempts also were made to consider the mediating role of various demographic variables, especially ethnic group membership, which has been associated both with media behaviors (e.g., Blosser, 1988; Greenberg, 1993) and with sexual outcomes (e.g., Day, 1992; Scott-Jones and White, 1990; Ward and Wyatt, 1994). The underlying premise is that media portrayals help shape young people's attitudes and assumptions about sexual relationships by creating a sense of what is normative and expected. Working as a "super peer," television helps define students' romantic and sexual ideals and serves as a template of how relationships could and should be.

\section{METHOD}

\section{Participants}

Participants were 269 undergraduates (64\% female) aged $18-22(M=20.3$ years $)$ who agreed to participate without knowledge of the topic as part of their Introduction to Psychology or Introduction to Developmental Psychology course experience. Students' responses to an open-ended question about their ethnic background revealed that $68 \%$ were White/European American, 15\% were Asian American or Middle Eastern, 10\% were African American, and 6\% were Latino/a.

In terms of their family backgrounds, $88 \%$ of the participants had been raised by a mother and a father (or by 2 grandparents), and $12 \%$ by a single parent. Information about parental education was obtained as a proxy for socioeconomic status. Data indicate that participants' parents were quite well-educated, with fathers averaging 17.0 years of schooling, and mothers averaging 16.0 years. Although this college sample was not representative of all emerging adults, it was an excellent population among which to study emergent sexuality because previous reports had indicated that $37 \%$ of this subject pool were virgins and 29\% had had only 1 sexual relationship (Ward and Rivadeneyra, 1999). Thus, this sample was expected to offer a nice mix of youth just beginning their sexual journeys and of others further along the way.

\section{Measures}

\section{Stimulus Clips}

The goal for the experimental component of the study was to compare the sexual attitudes of students exposed to nonsexual content to those of students exposed to sexual content featuring either dating as a game, women as sexual objects, or men as sex-driven creatures. To reach this end, stimulus clips were needed, depicting each of the 3 sexual stereotypes, as well as clips depicting nonsexual interactions. Individual clips were chosen from an archive of videotapes of popular sit-coms and dramas recorded in the 1992-93, 1995-96, and 1998-99 broadcast seasons. Material from popular sit-coms and dramas (e.g., Friends, Seinfeld, Ally McBeal) was selected to maximize external validity. A team of research assistants first screened dozens of TV episodes, marking examples of the focal sexual themes. All possible examples were then extracted and evaluated by members of the research team. Top candidates were then rated by an outside, 7-person, multiethnic panel of male and female graduate students. Panel members were asked to rate each of the 18 clips presented for the presence of any of the 3 sexual stereotypes under study. Clips were rated on a 7-point scale, anchored by 0 (not at all present) and 6 (strongly present). A clip was chosen as an appropriate representative of that theme if its mean rating fell at 3.0 (somewhat) or higher. This criterion was met for each of the 12 sexual clips. Mean ratings across the 4 clips for each sexual stereotype were as follows: (a) men 
are sex-driven - mean clip rating $=4.61$; (b) dating is a game - mean clip rating $=4.79$; (c) women are sexual objects - mean clip rating $=5.71$. The mean rating for each of the 6 neutral clips fell at or close to 0 , indicating that no evidence was detected of any of the sexual stereotypes under study.

Resulting from this search and evaluation were 4 clips depicting men as sex-driven creatures, 4 clips depicting dating as a game or recreational sport, 4 clips depicting women as sexual objects, and 6 neutral clips featuring nonsexual interactions between friends, siblings, or coworkers. Each clip was approximately $2-5 \mathrm{~min}$ in length. A 6-clip stimulus tape was then produced for each experimental condition by inserting 2 selected nonsexual scenes in with the 4 sexual scenes. The 6 nonsexual scenes served as the stimulus for the control condition.

\section{Television Viewing Behaviors}

Two dimensions of television use were examined: viewing amounts and viewer involvement. To assess viewing amounts, participants were asked about their viewing of prime-time comedies and dramas, daytime soap operas, and music videos. These particular genres were selected above other formats (e.g., news programming, sports) because of their emphasis on sexual relationships, and because of their inclusion of recurring characters or performers with whom viewers could potentially identify.

To measure viewing of prime-time sit-coms and dramas, a list was compiled of all network comedies and dramas that had aired regularly (at least 4 times) on 1 of the 6 major networks (ABC, CBS, NBC, Fox, UPN, and WB) over the past 6 weeks. Although students sample from many channels, the focus here was on the 6 major networks because these still attract the bulk of TV viewers (e.g., Bauder, 1998) and present the majority of fictional programs with recurring characters. Using a 5-point scale anchored by 0 (never/not this season) and 4 (every week), participants indicated how often they had viewed each of the 98 programs listed over the past 6 weeks. A similar paradigm was used to assess frequency of viewing soap operas. A list was provided of the 11 daytime soaps currently airing in that market, and participants were asked to indicate how frequently they viewed each one using 5 markers ranging from never/not this season to once a day/almost every day. Average monthly viewing amounts were then calculated for each genre on the basis of the frequencies with which each program was viewed and the length of the program.

Frequency of viewing music videos was assessed via 5 questions examining the number of hours participants watch music videos during the week (morning, afternoon, and evening), on Saturday, and on Sunday.
Weekly totals were calculated based on extrapolations from these data.

The 2nd group of measures assessed participants' general involvement in TV viewing. One measure examined students' motivations for watching TV, focusing on the following 2 dimensions: viewing for learning and viewing for entertainment. Participants were asked to rate each of 22 possible motivations for watching television comedies and dramas by using a 6-point scale that ranged from 1 (strongly disagree) to 6 (strongly agree). Individual motives had been extracted from previous research (Carveth and Alexander, 1985; Rubin, 1984; Sun and Lull, 1986), and included the following: "because they help me learn about myself and about others," "to help me understand the world," "because it's something fun to do with my friends," and "because they are exciting to watch." Ratings of agreement with the 11 learning motives were averaged to produce 1 Learning Motive score for each participant. Ratings of agreement with the 11 entertainment motives were averaged to produce 1 Entertainment Motive score for each person.

As a 2nd measure of viewer involvement, the Ward Active Viewing Measure (Ward and Rivadeneyra, 1999) was used to assess how active or passive each participant is as a television viewer. This is a 24-item instrument $(\alpha=0.91)$ that was created to examine the following 3 types of facilitative activity frequently outlined in the literature (Levy, 1983; Levy and Windahl, 1984; Rubin and Perse, 1987): selectivity in seeking specific TV programming, involvement during exposure, and postexposure use. Sample statements read as follows: "I often plan my day around the TV shows I like to watch," "I often try to guess what will happen next or how an episode will end," and "I frequently talk to others about what I have recently seen on TV." Agreement with each statement was rated using a 6-point scale that ranged from "not at all like me" to "very much like me." A mean Active Viewing score was calculated for each participant across the 24 items.

The final viewer involvement measure examined students' identification with each of 28 popular male and female TV characters. A list of 14 popular female characters (e.g., Rachel from Friends) and 14 popular male characters (e.g., John Carter from $E R$ ) was compiled based on Nielsen ratings of top programs and on undergraduates' viewing habits reported in pilot research. Participants were asked to rate the extent to which they identify with each character by using the following 4 markers: 1 - do not identify with at all; 2 - do not identify with; 3 - identify; 4 - strongly identify. The option was also given to respond N/A for any character with whom the participant was not familiar. Mean Female ID and Male ID scores were then calculated for each participant, taking into account both their ratings and the number of characters they had evaluated. 


\section{Sexual Outcome Measures}

Six sexual outcome variables were included to assess both students' attitudes about sexual relationships and their perceptions of their peers' sexual activities.

Attitudes About Sexuality. Participants' attitudes about dating, sexual roles, and romantic relationships were assessed using a revised version of the Attitudes Toward Dating and Relationships Measure (Ward and Rivadeneyra, 1999). This measure was especially appropriate because it had been created specifically to reflect themes about sexuality common both in the larger culture and on television. For this measure students were asked to rate their level of agreement with each of 36 statements reflecting the following 4 themes: dating is a game or recreational sport; men are sex-driven creatures; women are sexual objects; and sexual relationships center around religious dictates and traditional courtship norms. Responses were made using a 6-point scale that ranged from 1 (strongly disagree) to 6 (strongly agree).

Reliability analyses for this measure and its 4 subscales were conducted using a separate sample of 237 undergraduates. An alpha was first obtained for each subscale as initially conceptualized. Initial alphas ranged from 0.66 to 0.76 . Confirmatory factor analyses were then run to ensure that items for each subscale did indeed load together as 1 factor. Items that failed to load on the main factor (i.e., loaded at 0.39 or lower) or that cross-loaded on a different factor were removed. Resulting were the following scales: dating is a game -5 items, $\alpha=0.59$; men are sex-driven creatures -7 items, $\alpha=0.71$; women are sex objects -8 items, $\alpha=0.76$; and traditional courtship norms -5 items, $\alpha=0.69$. Because the subscale representing traditional courtship norms was not a focus of this study, it was not included in any analyses. Examples of statements representing the 3 focal stereotypes are included in the Appendix.

Attitudes About Gender Roles. To assess participants' general attitudes about the roles and appropriate behaviors of women and men, the Attitudes Toward Women Scale for Adolescents was used (Galambos et al., 1985). Respondents rated their level of agreement with each of 12 statements by using a 4-point scale. Sample statements include "Swearing is worse for a girl than for a boy," and "Boys are better leaders than girls." Scores were summed across the 12 items to yield a total score ranging from 12 to 48 , with higher scores reflecting more traditional attitudes toward gender. The authors report alphas levels of 0.78 and 0.72 for males and females in grades 6-12, which are comparable to the coefficients of 0.80 and 0.79 obtained among undergraduates tested in a previous study (Ward and Rivadeneyra, 1999).
Perceptions of Peers' Sexual Experiences. To assess participants' assumptions about the level of sexual activity among their peers, respondents were asked to estimate the percentage of males and the percentage of females who had engaged in each of 12 risk-related or recreational sexual behaviors (e.g., "have had sex on the first date," "have had more than 10 sexual partners"). These behaviors had been selected from general literature on sexual risks (e.g., Metzler et al., 1992). For each behavior, participants were asked to circle a number from 0 to 10 that reflected their sense of the number of males or the number of females out of every 10 who had engaged in that behavior by age 18 . Two scores were extracted from this measure. One score reflected the sum of the 12 estimates for male peers, and the other reflected the sum of the 12 estimates for female peers. Each score served as an overview of the level of recreational and risk-related sexual experience participants presumed of their peers.

To obtain general information about participants' own levels of experience with sexual relationships, the following question was asked: "How would you describe your current level of experience with dating and sexual relationships?" Responses were placed on an 11-point scale that included the following markers: just starting out (0 and 1), some dating (2 and 3), one sexual relationship (4 and 5), and have had several sexual relationships (6-10).

\section{Procedure}

Students participated either in groups of 25-30 during a portion of their class discussion sections or in small groups of 8-10 as part of their experiential requirement for Introduction to Psychology. Each group was randomly assigned to 1 of the 3 experimental conditions or to the control condition until all groups had been tested. Differences in class sizes lead to differences in cell sizes. Each group was first introduced to the study by a standard protocol that was read verbatim and indicated that the experiment examined people's perceptions of social relationships as portrayed on TV and in real life. Questionnaire packets were then distributed, and each group was shown a set of 6 clips. In keeping with the premise of the study, students were asked to rate each clip as it aired on the following 3 dimensions: (1) "How entertaining or funny is this clip?" (2) "How realistic do you believe the actions are?" (3) "To what extent can you identify with the characters?" Participants were also asked to indicate if they had seen the clip or particular episode before or had participated in a similar study. After viewing and evaluating the clips, participants completed the battery of outcome measures that assessed their attitudes about dating and sexual relationships, their assumptions about the level of sexual activity among their 
peers, and their endorsement of traditional gender role attitudes. Finally, participants responded to measures examining their regular media exposure and their demographic backgrounds. Students were then thanked for their participation and either dismissed from the small group or led in class discussion as usual. Each session lasted approximately $45 \mathrm{~min}$.

\section{RESULTS}

\section{Descriptives and Preliminary Analyses}

Descriptive statistics for the key independent and dependent variables are provided in Table I. Because sex differences are often reported in both adolescent media use and sexual attitudes (e.g., Greenberg et al., 1993; Ward and Rivadeneyra, 1999), means are reported both for the whole sample and for each sex, and all analyses are conducted separately by sex.

For this college sample, viewing habits varied widely. Although students reported watching prime-time sit-coms and dramas for an average of only $18 \mathrm{~h}$ a month, this figure ranged from 0 ( $2 \%$ of the sample) to $87 \mathrm{~h}$. Time spent watching music videos was also quite variable, ranging from 0 (26\% of the sample) to $40 \mathrm{~h}$ a week ( $2 \%$ of the sample), with a mean of $9 \mathrm{~h}$. However, as this was a weekly count, the monthly mean of $36 \mathrm{~h}$ indicates that music video exposure is a substantial portion of undergraduates' media use.

For the sexuality variables, students' agreement with each of the 3 sexual stereotypes was typically quite low.
On the 1-6 scale provided in which a 6 represented strong agreement, none of the 3 means surpassed 3.0. For the background variable representing level of personal sexual experience, the mean of 4.97 suggests that on average, students have had only 1 sexual relationship. However, the $32 \%$ of students reporting scores of $0,1,2$, or 3 have had none.

As expected, significant sex differences emerged for a number of the media and sexuality variables (see Table I). While women watched soap operas more often than men did, men watched more hours of music videos. Women were also more active viewers and identified more strongly with popular female characters; men identified more strongly with popular male characters. Men and women also differed in their sexual attitudes and assumptions. In comparison to men, women were less traditional in their gender role attitudes, less supportive of the 3 sexual stereotypes, and assumed more sexual experience of their male peers. The sexes did not differ, however, in their levels of personal experience with dating and sexual relationships.

The second series of preliminary analyses examined zero-order correlations between the background variables and the sexual outcome variables. Results are reported by sex and are summarized in Table II. For the female participants, ethnic group membership was the most frequent correlate of their sexual attitudes and perceptions, but not in a coherent way. Being Asian correlated with stronger agreement that women are sex objects, while being Latina correlated with greater acceptance of dating as a game. Being Asian was also associated with lower

Table I. Descriptives of Central Independent and Dependent Variables

\begin{tabular}{|c|c|c|c|c|c|}
\hline & Sample mean & Standard deviation & Female mean & Male mean & Sex difference \\
\hline \multicolumn{6}{|l|}{ Viewing habits } \\
\hline Prime hours/month & 17.92 & 12.91 & 18.75 & 16.46 & ns \\
\hline Soap hours/month & 5.35 & 9.05 & 7.54 & 1.53 & $F=30.46^{* * *}$ \\
\hline Music video hours/week & 9.02 & 10.49 & 7.69 & 11.33 & $F=7.71^{* *}$ \\
\hline Total hours/month & 59.33 & 50.86 & 57.04 & 63.33 & ns \\
\hline Active viewing & 3.08 & 0.81 & 3.17 & 2.92 & $F=5.74^{*}$ \\
\hline Learning motive & 2.41 & 0.94 & 2.38 & 2.45 & ns \\
\hline Entertainment motive & 4.01 & 0.81 & 4.06 & 3.91 & ns \\
\hline ID with female TV characters & 1.86 & 0.93 & 2.18 & 1.29 & $F=73.25^{* * *}$ \\
\hline ID with male TV characters & 2.02 & 0.86 & 1.90 & 2.23 & $F=9.01^{*}$ \\
\hline \multicolumn{6}{|l|}{ Sexuality variables } \\
\hline Traditional gender role attitudes & 19.10 & 5.02 & 16.82 & 23.07 & $F=150.54^{* * *}$ \\
\hline Females are sex objects & 2.77 & 0.78 & 2.46 & 3.32 & $F=102.81^{* * *}$ \\
\hline Males are sex-driven & 2.84 & 0.78 & 2.62 & 3.23 & $F=44.32^{* * *}$ \\
\hline Dating is a game/recreation & 2.43 & 0.81 & 2.21 & 2.84 & $F=40.66^{* * *}$ \\
\hline Presumed sexual experience of female peers & 38.11 & 13.55 & 38.70 & 37.09 & ns \\
\hline Presumed sexual experience of male peers & 50.20 & 15.19 & 51.98 & 47.13 & $F=6.44^{*}$ \\
\hline Own sexual experience & 4.97 & 2.33 & 4.88 & 5.12 & ns \\
\hline
\end{tabular}

${ }^{*} p<0.05 ;{ }^{* *} p<0.01 ;{ }^{* * *} p<0.001$. 
Table II. Zero-Order Correlations Between Background Variables and Sexual Outcome Variables

\begin{tabular}{|c|c|c|c|c|c|c|c|c|}
\hline & Age & Asian & Black & Latina & MomEd & DadEd & SPFam & Sex. Exp. \\
\hline \multicolumn{9}{|l|}{ Females $(n=166-169)$} \\
\hline \multicolumn{9}{|l|}{$\begin{array}{l}\text { Traditional gender } \\
\text { role attitudes }\end{array}$} \\
\hline \multicolumn{9}{|l|}{ Men are sex-driven } \\
\hline Women are sex objects & & $0.19^{*}$ & & & & & & \\
\hline Dating is a game & & & & $0.18^{*}$ & & & & $0.25^{* * *}$ \\
\hline $\begin{array}{l}\text { Presumed sexual experience } \\
\text { of Male peers }\end{array}$ & & & $0.24^{*}$ & & & $-0.19^{*}$ & & \\
\hline $\begin{array}{l}\text { Presumed sexual experience } \\
\text { of Female peers }\end{array}$ & & $-0.16^{*}$ & $0.24^{*}$ & & & & $-0.15^{*}$ & \\
\hline \multicolumn{9}{|l|}{ Males $(n=96-98)$} \\
\hline \multicolumn{9}{|l|}{$\begin{array}{l}\text { Traditional gender } \\
\text { role attitudes }\end{array}$} \\
\hline Men are sex-driven & $-0.20^{*}$ & & & & & & & $0.38^{* * *}$ \\
\hline Women are sex objects & $-0.24^{*}$ & & $0.26^{* *}$ & & & $0.22^{*}$ & & $0.31^{* *}$ \\
\hline Dating is a game & $-0.21^{*}$ & & $0.28^{* *}$ & & & & & $0.40^{* * *}$ \\
\hline $\begin{array}{l}\text { Presumed sexual experience } \\
\text { of Male peers }\end{array}$ & & & $0.21^{*}$ & & & & & $0.41^{* * *}$ \\
\hline $\begin{array}{l}\text { Presumed sexual experience } \\
\text { of Female peers }\end{array}$ & & & $0.28^{* *}$ & & $-0.19^{\dagger}$ & & & $0.36^{* * *}$ \\
\hline
\end{tabular}

Note. MomEd - Mom's Education; DadEd - Dad's Education; SPFam - Single-parent family; Sex. Exp. - Sexual experience. ${ }^{*} p<0.05 ;{ }^{* *} p<0.01 ;{ }^{* * *} p<0.001 ;{ }^{\dagger} p<0.06$

expectations of the level of sexual experience of female peers; being Black was associated with higher expectations about peers' sexual experiences. A more consistent set of relationships emerged among the male participants. Here, being younger, Black, and more sexually experienced were each associated with stronger endorsement of the 3 sexual stereotypes. Moreover, Black men and males with more sexual experience also assumed higher levels of experience of their peers.

A final group of preliminary analyses tested the equality of the stimuli across conditions. Of chief concern was whether differences existed by condition in how entertaining the clips were perceived to be, or in participants' previous exposure to those episodes or to a similar experiment. Analyses of variance revealed no differences by condition in the entertainment value of the clips, $F(3,268)=1.11$, $p=0.34$, nor in students' previous participation in a related experiment, $F(3,267)=1.29, p=0.27$. However, prior clip exposure did vary by condition, $F(3,268)$, = $7.55, p<0.000$, such that clips in the control and in the "men are sex-driven" conditions were more likely to have been seen before. As a result, the clip exposure variable was entered as a control in later analyses.

\section{Testing of the Main Research Questions}

One goal of this study was to confirm that regular viewing exposure and involvement are both associated with viewers' attitudes and perceptions about sexual relationships. Correlational analyses were run examining associations between the 4 viewing amount variables, the 5 viewer involvement variables, and the 6 sexual outcome variables. Separate analyses were run for each sex, with exposure to the experimental primes controlled. Results are summarized in Table III.

Among the female participants, several positive correlations emerged, each indicating that greater media exposure and media involvement were associated with stronger endorsement of the sexual stereotypes tested or with higher expectations concerning peer sexual experiences. Indeed, 32 of the 54 correlations run were statistically significant. Most consistent were results examining women's endorsement of the 3 sexual stereotypes: females are sex objects, males are sex-driven, and dating is a game. For each theme, women who viewed more hours of music videos and prime-time programming, who watched TV intently either for entertainment or for learning purposes, and who identified more strongly with TV's popular female characters were also more likely to support these notions about sexual relationships. While the correlations hover around the small-to-moderate range of 0.16-0.32, their strength comes in their consistency.

Similar trends emerged among the male participants, although not quite as regularly. For men, viewing amounts appeared to be a stronger force than viewer involvement, with much of the contribution carried by music video 
Table III. Partial Correlations Between Media Exposure and Media Involvement Variables and Sexual Outcomes (Controlling for Experimental Exposure)

\begin{tabular}{|c|c|c|c|c|c|c|}
\hline & $\begin{array}{l}\text { Traditional gender } \\
\text { role attitudes }\end{array}$ & $\begin{array}{c}\text { Females are } \\
\text { sex objects }\end{array}$ & $\begin{array}{l}\text { Males are } \\
\text { sex driven }\end{array}$ & Dating is a game & $\begin{array}{l}\text { Presumed sex. exp. } \\
\text { of male peers }\end{array}$ & $\begin{array}{l}\text { Presumed sex. exp. } \\
\text { of female peers }\end{array}$ \\
\hline \multicolumn{7}{|l|}{ Females $(n=157-168)$} \\
\hline Prime time hours & $0.16^{*}$ & $0.22^{* *}$ & $0.22^{* *}$ & $0.16^{*}$ & & \\
\hline Soap opera hours & & & & & $0.26^{* * *}$ & $0.27^{* * *}$ \\
\hline Music video hours & & $0.25^{* * *}$ & $0.16^{*}$ & & $0.19^{* *}$ & $0.18^{*}$ \\
\hline Total viewing hours & $0.16^{*}$ & $0.28^{* * *}$ & $0.21^{* *}$ & $0.17^{*}$ & $0.23^{* *}$ & $0.21^{* *}$ \\
\hline Active viewing & & $0.17^{*}$ & & & & \\
\hline Entertainment motive & $0.26^{* * *}$ & $0.32^{* * *}$ & $0.28^{* * *}$ & $0.23^{* *}$ & $0.19^{*}$ & $0.20^{* *}$ \\
\hline Learning motive & $0.27^{* *}$ & $0.24^{* *}$ & $0.21^{* *}$ & $0.18^{*}$ & & $0.16^{*}$ \\
\hline ID with TV females & & $0.25^{* * *}$ & $0.27^{* * *}$ & $0.23^{* *}$ & & \\
\hline ID with TV males & & & $0.16^{*}$ & & & \\
\hline \multicolumn{7}{|l|}{ Males $(n=88-95)$} \\
\hline Prime time hours & & $0.22 *$ & & & $0.22^{*}$ & \\
\hline Soap opera hours & & & & & $0.21^{*}$ & \\
\hline Music video hours & $0.22^{*}$ & $0.23^{*}$ & $0.185^{\dagger}$ & $0.34^{* * *}$ & $0.36^{* *}$ & $0.21^{*}$ \\
\hline Total viewing hours & $0.22^{*}$ & $0.25^{*}$ & & $0.32^{* * *}$ & $0.38^{* * *}$ & \\
\hline Active viewing & & $0.31^{* *}$ & & & & \\
\hline \multicolumn{7}{|l|}{ Entertainment motive } \\
\hline Learning motive & $0.27^{* *}$ & & & & & \\
\hline \multicolumn{7}{|l|}{ ID with TV females } \\
\hline ID with TV males & & & & & & \\
\hline
\end{tabular}

${ }^{*} p<0.05{ }^{* *} p<0.01 ;{ }^{* * *} p<0.001 ;{ }^{\dagger} p<0.075$ (used for males only).

consumption. Here, the more hours of music videos men watched, the more strongly they endorsed each of the gender and sexual stereotypes examined. Frequent viewing among males was also associated with higher expectations of the level of sexual experience of their peers, and of male peers, especially.

A central goal of this study was to assess whether viewing certain sexual stereotypes affects viewers' subsequent acceptance of those stereotypes, and whether this relationship varies based on participants' regular viewing habits. In other words, would students in the experimental groups be more inclined than students in the control group to endorse the sexual stereotypes presented? Would this effect exist for both frequent and infrequent viewers? To answer these questions, a set of $2 \times 2$ analyses of covariance was run comparing endorsement of the sexual stereotypes across Viewing Condition and across PrimeTime Viewing Amounts segmented into Low, Moderate, and High. ${ }^{3}$ Number of stimulus clips/episodes seen previously served as a covariate in each analysis. Separate analyses were run for each sex; results are presented in Table IV. Because no interaction terms were significant, only means for the main effects are reported.

3"Low" viewers watched $0-9.5 \mathrm{~h}$ of prime-time sit-coms and dramas per month $(29.7 \%$ of the sample); "Moderate" viewers watched 10 $21.5 \mathrm{~h} /$ month (37.5\%); "High" viewers watched $\geq 22 \mathrm{~h} /$ month (32.7\%).
The results are quite striking. For each of the 3 sexual stereotypes examined, female participants in the experimental group offered significantly stronger endorsement of the stereotype than did females in the control group. At the same time, women who normally view high amounts of prime-time sit-coms and dramas offered significantly stronger endorsement of the stereotypes than did women who view low amounts. These factors did not interact, indicating that the effects of the experimental exposure worked equally for all women, regardless of their normal viewing amounts. Male participants, however, seemed unaffected by viewing these clips. Endorsement of the sexual stereotypes was equally strong among men in the experimental and control groups, and among men who view low and high amounts of prime-time programming. Thus, exposure to TV's sexual stereotypes does appear to affect viewers' acceptance of those stereotypes, but only among women.

As a final test of connections between media use and students' sexual attitudes and assumptions, regression analyses were run in which the background and media variables were examined simultaneously as predictors of the sexual outcome variables. A separate analysis was conducted for each of the 4 sexual attitude variables and the 2 peer norm variables. Included in each equation were any of the 8 demographic background variables and any of the 8 media use variables (excluding total hours 
Table IV. Comparison of Participants' Endorsements of Specific Sexual Themes by Viewing Condition and by Regular Viewing Amounts

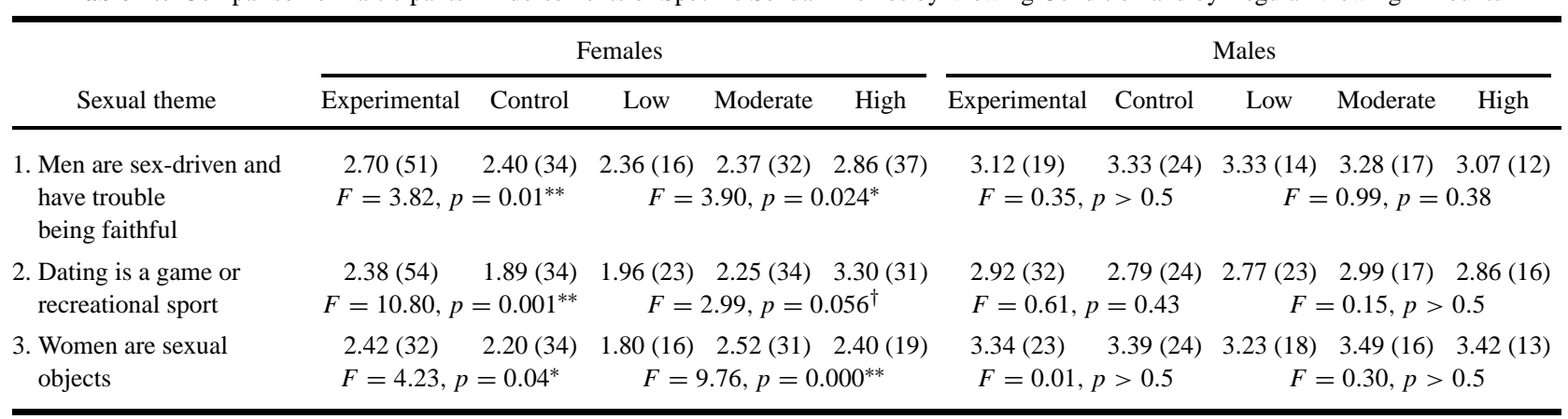

Note. Attitudes were measured on a 6-point scale, with higher scores indicating stronger endorsement of that theme. Numbers in parentheses following each mean represent the cell size. All analyses controlled for the number of clips/episodes seen previously.

${ }^{*} p \leq 0.05 ;{ }^{* *} p \leq 0.01 ;{ }^{\dagger} p \leq 0.06$.

because of concern for multicollinearity) that had correlated with that sexual outcome variable at the 0.06 level or stronger (as indicated in Tables II and III). A variable representing membership in any of the 3 experimental conditions was also included in each equation to examine contributions of the media prime. ${ }^{4}$ Separate equations were designed for each sex. Thus, with these analyses, the central question read as follows: Which is a stronger predictor of students' current attitudes and assumptions about sexual relationships: their immediate exposure to those messages, their regular media usage, or something in their general background (i.e., demographics or sexual experience) $?^{5}$

Results summarized in Tables V and VI indicate that each equation tested was statistically significant, with the predictors accounting for $8.3-26.1 \%$ of the variance. Again, the nature of the relationships varied by gender. Among women, the 2 factors that most consistently predicted their acceptance of the sexual stereotypes were a stronger usage of TV for entertainment and exposure to a stereotype prime. Ethnic group membership played a slight role, as did women's own level of experience

\footnotetext{
${ }^{4}$ Because the sexual stereotypes presented across the 3 experimental conditions were highly related both conceptually and in participants' own minds (with correlations ranging from 0.45 to 0.60 for women and 0.60 to 0.67 for men), exposure to any one could potentially trigger thoughts about the others. In consideration of this possibility, the media prime variable used in these analyses examined exposure to any of the 3 experimental themes.

${ }^{5}$ Although interactions between Viewing Condition and Prime-Time Viewing Amounts were not significant in the ANOVAs, an interaction term was initially included in the regression analyses to continue to examine whether the media prime affects all groups equally. However, the interaction term never emerged as a significant predictor and was subsequently dropped from each equation.
}

with dating and sexual relationships. Surprisingly, regular viewing amounts contributed little, with results indicating only that watching more hours of music videos predicted stronger agreement that women are sexual objects.

A different set of variables predicted women's assumptions about the sexual experiences of their peers. Here, experimental exposure and entertainment motives were irrelevant. Instead, demographic factors and regular soap opera viewing figured prominently. Concerning women's beliefs about their female peers, being Asian and from a single-parent family predicted lower expectations, while being Black or a frequent soap opera viewer predicted higher expectations. In estimating the level of sexual experience of their male peers, having a more educated father predicted lower numbers and frequent soap opera viewing predicted higher numbers.

Among the male participants (see Table VI), the most consistent predictor of their sexual attitudes was their level of experience with sexual relationships. Here, having more personal experience in this arena predicted greater endorsement of each of the 3 sexual stereotypes. At the same time, frequent viewing of music videos predicted stronger endorsement of traditional gender role norms and of dating as a game/sport. No consistent patterns were apparent for the remaining results. However, while experimental exposure appeared earlier to have no impact on men's attitudes, here it was a notable contributor to their acceptance of dating as a game.

The final two equations examined factors predicting men's assumptions about the sexual experiences of their peers. Contributing most to men's beliefs that their male peers are sexually experienced were greater levels of personal experience in the dating arena, exposure to any of the stereotypical primes, and music video viewing. Factors contributing most to men's beliefs about the sexual 
Table V. Summary of Simultaneous Regression Analyses Examining Contributions of Demographics, Media Use, and Experimental Exposure to Women's Sexual Attitudes and Expectations (Unstandardized and Standardized Regression Coefficients Reported)

\begin{tabular}{|c|c|c|c|c|c|c|c|c|c|c|c|c|}
\hline & \multicolumn{8}{|c|}{ Attitudes about sexual relationships } & \multicolumn{4}{|c|}{ Assumptions about peer experiences } \\
\hline & \multicolumn{2}{|c|}{ Gender roles } & \multicolumn{2}{|c|}{ Males are sex-driven } & \multicolumn{2}{|c|}{ Females are sex objects } & \multicolumn{2}{|c|}{ Dating is a game } & \multicolumn{2}{|c|}{ Female peers } & \multicolumn{2}{|c|}{ Male peers } \\
\hline \multicolumn{13}{|l|}{ Age } \\
\hline Asian & & & & & 0.31 & $0.18^{*}$ & & & -5.52 & $-0.15^{*}$ & & \\
\hline Black & & & & & & & & & 10.31 & $0.22^{* *}$ & 7.55 & 0.13 \\
\hline Latino/a & & & & & & & 0.55 & $0.18^{*}$ & & & & \\
\hline \multicolumn{13}{|l|}{ Mother's education } \\
\hline Father's education & & & & & & & & & & & -0.82 & $-0.15^{\dagger}$ \\
\hline Single-parent family & & & & & & & & & -6.39 & $-0.16^{*}$ & & \\
\hline Sexual experience & & & & & & & 0.05 & $0.16^{*}$ & & & & \\
\hline Prime hours & 0.01 & 0.05 & 0.00 & 0.05 & -0.00 & -0.01 & -0.00 & -0.01 & & & & \\
\hline Soap hours & & & & & & & & & 0.28 & $0.21^{* *}$ & 0.31 & $0.20^{*}$ \\
\hline Music video hours & & & 0.00 & 0.07 & 0.01 & $0.15^{*}$ & & & 0.06 & 0.04 & 0.11 & 0.07 \\
\hline Active viewing & & & & & -0.04 & -0.06 & & & & & & \\
\hline Entertainment motive & 0.68 & $0.15^{\dagger}$ & 0.15 & $0.18^{*}$ & 0.18 & $0.25^{* *}$ & 0.19 & $0.21^{*}$ & 1.89 & 0.11 & 2.25 & 0.12 \\
\hline Learning motive & 0.77 & $0.20^{*}$ & 0.04 & 0.05 & 0.04 & 0.06 & 0.05 & 0.06 & 0.84 & 0.06 & & \\
\hline ID with TV females & & & 0.14 & 0.13 & 0.08 & 0.08 & 0.07 & 0.07 & & & & \\
\hline ID with TV males & & & -0.02 & -0.02 & & & & & & & & \\
\hline Exptl. exposure & -0.77 & -0.09 & 0.29 & $0.17^{*}$ & 0.33 & $0.22^{* *}$ & 0.32 & $0.18^{*}$ & 1.69 & 0.05 & 0.45 & 0.01 \\
\hline Adjusted $R^{2}$ & & 83 & & 91 & & .179 & 0.1 & & 0.1 & 60 & 0.1 & \\
\hline$F$ & & & & 66 & & .33 & 5.1 & & 4.7 & 73 & 4.5 & \\
\hline Significance & & & & 03 & & .000 & 0.0 & & 0.0 & & 0.0 & \\
\hline
\end{tabular}

${ }^{*} p<0.05 ;{ }^{* *} p<0.01 ;{ }^{\dagger} p<0.08$.

Table VI. Summary of Simultaneous Regression Analyses Examining Contributions of Demographics, Media Use, and Experimental Exposure to Men's Sexual Attitudes and Expectations (Unstandardized and Standardized Regression Coefficients Reported)

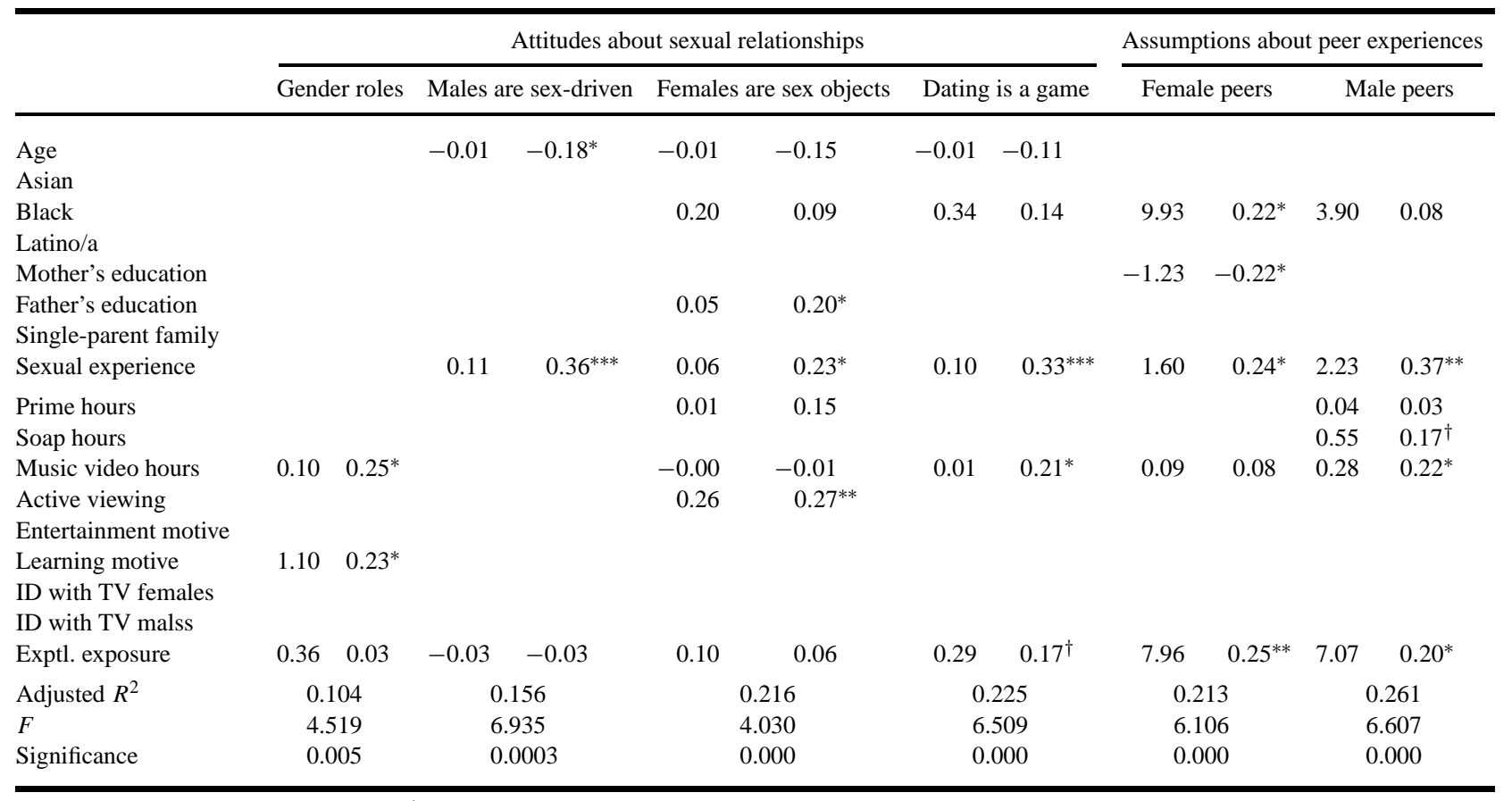

${ }^{*} p<0.05 ;{ }^{* *} p<0.01 ;{ }^{* * *} p<0.001 ;{ }^{\dagger} p<0.08$. 
experiences of their female peers were more personal experience with sexual relationships, exposure to a stereotypical prime, being an African American, and having a less educated mother.

\section{DISCUSSION}

The goal of this study was to seek experimental and correlational confirmation of television's influence on students' attitudes and assumptions about sexual relationships. Both viewing amount and viewer involvement were examined for their contributions to several forms of students' sexual conceptions. A number of significant relations emerged, each indicating positive associations between media exposure and students' beliefs about sexual relationships.

Confirming earlier findings (e.g., Ward and Rivadeneyra, 1999), both heavier TV exposure and deeper viewer involvement were consistently correlated with attitudes that sexual relationships are recreationally oriented, that men are sex-driven, and that women are sexual objects. These are the messages about sexuality reported to occur most frequently on TV (Ward, 1995), and these stereotypes were less likely to be rejected by heavier and more involved viewers, especially young women. At the same time, more frequent TV exposure contributed to greater expectations of peer sexual experience, lending support to the notion that "everyone is doing it."

Extending the power of these correlational findings are experimental outcomes that suggest much of the same. When exposed to several entertaining clips that featured these sexual stereotypes, female students later offered stronger endorsement of these themes than did women exposed to equally entertaining but nonsexual clips. Regardless of their regular viewing amounts, women's beliefs about relationships appeared to be shaped by exposure to these stereotypical portrayals. Experimental exposure continued to make a strong contribution to women's attitudes in regression analyses that also included contributions from demographics, regular viewing habits, and existing sexual experiences. Thus, while correlational findings are sometimes devalued because causal linkages are ambiguous, experimental evidence that reports the same outcome is harder to dismiss. While the effects produced by this 1 exposure are likely to be short-lived, they are also likely to be repeated because the stimuli that produced them were drawn from programming frequently viewed by college students (e.g., Friends, Seinfeld). With each activation, that particular schema or way of viewing the world grows stronger, more accessible, and more valid.
Indeed, several dimensions of women's and men's regular media use predicted their support of these stereotypes, suggesting that this is not simply a laboratory phenomenon. Figuring most prominently for women was their intentional viewing of comedies and dramas for entertainment purposes, which predicted women's support of each of the 3 sexual stereotypes. It is possible, then, that women who watch these genres to be entertained may also do so less critically and consciously, soaking in the amusing messages without critiquing them. Frequent viewing of music videos also figured prominently. Among women, it predicted stronger endorsement that females are sexual objects; among men, it predicted endorsing more traditional attitudes about gender roles, viewing dating as a recreational sport, and presuming greater sexual experience of their male peers. Indeed, this genre appears to be a particularly potent force in shaping the sexual beliefs of young men, who watched an average of $45 \mathrm{~h}$ of music videos each month, 15 more hours than women. Overall, these findings illustrate that television's role in shaping viewers' beliefs about sexuality is neither simple nor direct, and instead appears to vary by the sex of the participant, and by the sexual outcome and form of media use under consideration.

Media use, however, was only 1 contributor; also playing a role were students' preexisting levels of experience with sexual relationships. Results indicated that having more personal experience in this arena predicted stronger acceptance of the sexual stereotypes studied, especially among men. While it is typically assumed that the sexually inexperienced male would be most likely to accept these stereotypes, it appears that young men with "experience" are the ones more likely to endorse them. It is unclear, however, if relationship experience strengthens the stereotypes, or if men who endorse the stereotypes more actively seek out relationship experiences. Indeed, if one agrees that men are sex-driven, women are sexual objects, and dating is a recreational sport, then living by these rules and assertively seeking out sexual relationships follows logically.

One intriguing pattern to address is the sex differences in the findings, with fewer and weaker connections emerging among men for both the correlational analyses and the experimental outcomes. Sample size may be part of the issue, given that several of the men's experimental cells were half the size of women's. However, other factors may have contributed to this gender gap. For example, because men were more likely than women to endorse each of the 3 sexual stereotypes, it may have been difficult to produce stronger agreement with statements that were already supported. Indeed, men's means were consistently 
higher than women's, and even women exposed to the experimental primes never reached the levels of agreement reported by the control males. It may also be an issue of genre. Frequency of viewing prime-time programs and exposure to clips drawn from prime-time programming were minimally associated with men's sexual attitudes here, confirming earlier findings (Ward and Rivadeneyra, 1999). However, it may not be that $T V$ affects men less than women, but that the particular genres selected for examination hold less influence with men than with women. Indeed, given the strong experimental effects reported by Rudman and Borgida (1995) who exposed men to sexist commercials, and the apparent power of music video consumption suggested here, it may be premature to exclude males from the equation. Instead, an appropriate next step would be to explore the impact on men's sexual attitudes of more male-oriented genres such as music videos, video games, and men's magazines (e.g., Maxim).

Finally, stronger outcomes for women may also be a consequence of society's contradictory messages about female sexuality that encourage women to be sexually attractive yet not sexually active. As a result of this contradiction, many speculate that women must continually work to decipher society's expectations of them (D. Tolman, personal communication, 1999), and may be especially open to accepting portrayals from the media as clarification. Much of the content of women's magazines is geared toward this purpose, with articles frequently focusing on how to attract men, read their signals, and hone relationships skills (Durham, 1998; Garner et al., 1998). In this medium, success as a woman hinges on success in "landing a husband." By contrast, cultural messages about male sexuality are more consistent, and success as a man depends less on one's romantic status than on one's occupational and financial status.

Although the results described here indicate a link between media exposure and students' conceptions about sexual relationships, additional work is needed to address the limitations of this study and to advance the field in general. For example, a diversification of participants is necessary to begin to understand the contributions of class, ethnic group membership, and peer group culture. Would the same patterns emerge among a predominantly Black or Latino sample or among emergent adults not in college? It would also be informative to examine how these processes work among younger adolescents whose media diets and orientations to sexual relationships differ from those of emerging adults. In adolescence, sexual knowledge and analytical skills are less advanced, desires for intimacy and long-term commitments are less pressing, and input and constraints from parents carry more weight. In contrast, college students living away from home have tremendous freedom from their parents and must learn to negotiate sexual risk-taking in a complex environment where alcohol is prevalent, and where peers and dating partners are especially influential (Christopher, 2001; Cohen and Lederman, 1998). Consequently, it is possible that with more opportunity, less parental constraint, and more sexualized peer norms, the contributions uncovered here may be more influential among emergent adults than among younger adolescents. Additional work is needed, examining developmental trends in these issues.

One important implication of these findings is their potential role in sexual decision-making. How might believing that males are sex-driven, that women are sexual objects, that dating is a game, and that "everyone is doing it" inform college students' sexual decision-making? As noted earlier, endorsing these types of beliefs is associated with less effective contraceptive use, an earlier age of sexual activity, and more and riskier sexual experiences (e.g., Fox, 1977). Other implications may also follow. For example, will women who believe their role is to be a sexual object feel less comfortable acting as a sexual subject- taking control, exerting iniative, and rejecting advances? Does believing that men are sex-driven (e.g, "boys will be boys") encourage women to endure infidelities, disrespectful behavior, and sexual harrassment? How does sensing intense pressure to be sexually active shape men's sexual choices? Accordingly, a critical next step would be to model how students' attitudes and assumptions about sexual relationships, informed partly by the media as demonstrated here, go on to influence their sexual behaviors and sexual decisionmaking.

In conclusion, television presents a wealth of exciting, amusing, provocative, and disturbing fictional images of human sexual relationships. The content of these portrayals would be inconsequential if they in no way influenced viewers' attitudes and assumptions about sexual relationships in the real world. However, evidence presented here points to the contrary. Although the connections uncovered are complex, this study presents both correlational and experimental evidence that TV's narrow portrayals appear to strengthen sexual stereotypes and heighten assumptions of peer sexual experience. These findings are additionally powerful, given mounting evidence that youths' assumptions about the sexual roles of women and men do affect their sexual-decision making. Thus, while watching television may seem like harmless entertainment, the implications of its images are farreaching. 


\section{APPENDIX: FINAL SUBSCALES FOR ATTITUDES ABOUT DATING AND SEXUAL RELATIONSHIPS MEASURE}

1. Men are sex-driven and have trouble being faithful.

- Men are mostly interested in women as potential sex partners and don't want to be "just friends" with a woman.

- It's difficult for men to resist sexual urges and to remain monogamous.

- It is natural for a man to want to admire or ogle women and to comment on their bodies, even if he has a girlfriend.

- Something is wrong with a guy who turns down a chance to have sex.

- Men who are "good with the ladies" and who can get any woman into bed are cool.

- Men are always ready and willing for sex; they think about it all the time.

- It is only natural for a man to make sexual advances to a woman he finds attractive.

2. Dating is a game or recreational sport.

- Dating is basically a game, a battle of the sexes, where both males and females try to gain the upper hand and manipulate each other.

- Sexual activity is desirable as early in a relationship as possible.

- A good way to reward or punish someone is by giving or withholding sex.

- You don't need a relationship to have good sex; all you need are two people who are attracted to each other.

- A man will be most successful in meeting or picking up women if he has a "rap" or uses flattering, sexy, or cute pick-up lines.

3. Women are sexual objects whose value is based on their physical appearance.

- An attractive woman should expect sexual advances and should learn how to handle them.

- Women should be more concerned about their appearance than men.

- Using her body and looks is the best way for a woman to attract a man.

- Women should spend a lot of time trying to be pretty; no one wants to date a woman who has "let herself go."

- There's nothing wrong with men whistling at shapely women.

- It bothers me when a man is interested in a woman only if she is pretty (reverse coded).

- There is nothing wrong with men being primarily interested in a woman's body.
- Being with an attractive woman gives a man prestige.

\section{REFERENCES}

Andre, T., Frevert, R. L., and Schuchmann, D. (1989). From whom have college students learned about sex? Youth Soc. 20: 241-268.

Arnett, J. J. (2000). Emerging adulthood: A theory of development from the late teens through the twenties. Am. Psychol. 55: 469-480.

Baran, S. J. (1976). How TV and film portrayals affect sexual satisfaction in college students. Journalism Q. 53: 468-473.

Bauder, D. (1998). Cable ratings top networks. The Washington Post, July 8 , p. D7.

Blosser, B. J. (1988). Ethnic differences in children's media use. J. Broadcasting Electron. Media 32: 453-470.

Brown, J. D., and Newcomer, S. F. (1991). Television viewing and adolescents' sexual behavior. J. Homosexuality 21: 77-91.

Brown, J. D., and Steele, J. R. (1995). Sex and the Mass Media. Kaiser Family Foundation, Menlo Park, CA.

Bryant, J., and Rockwell, S. C. (1994). Effects of massive exposure to sexually oriented prime-time television programming on adolescents' moral judgment. In Zillman, D., Bryant, J., and Huston, A. C. (eds.), Media, Children, and the Family: Social Scientific, Psychodynamic, and Clinical Perspectives. Erlbaum, Hillsdale, NJ, pp. 183-195.

Buerkel-Rothfuss, N. L., and Strouse, J. S. (1993). Media exposure and perceptions of sexual behaviors: The cultivation hypothesis moves to the bedroom. In Greenberg, B. S., Brown, J. D., and BuerkelRothfuss, N. L. (eds.), Media, Sex, and the Adolescent. Hampton Press, Creskill, NJ, pp. 225-247.

Calfin, M. S., Carroll, J. L., and Shmidt, J. (1993). Viewing musicvideotapes before taking a test of premarital sexual attitudes. Psychol. Rep. 72: 475-481.

Carveth, R., and Alexander, A. (1985). Soap opera viewing motivation and the cultivation process. J. Broadcasting Electron. Media 29: 259-273.

Christopher, F. S. (2001). To Dance the Dance: A Symbolic Interactional Exploration of Premarital Sexuality. Erlbaum, Mahwah, NJ.

Cohen, D. J., and Lederman, L. C. (1998). Navigating the freedoms of college life: Students talk about alcohol, gender, and sex. In Roth, N. L., and Fuller, L. K. (eds.), Women and AIDS: Negotiating Safer Practices, Care, and Representation. The Hawforth Pres, New York.

Day, R. D. (1992). The transition to first intercourse among racially and culturally diverse youth. J. Marr. Fam. 52: 749-762.

DiOrio, C., Kelley, M., and Hockenberry, M. (1999). Communication about sexual issues: Mothers, fathers, and friends. J. Adolesc. Health 24: 181-189.

Dorr, A. (1986). Television and Children: A Special Medium for a Special Audience. Sage, Beverly Hills, CA.

Durham, M. (1998). Dilemmas of desire: Representations of adolescent sexuality in two teen magazines. Youth Soc. 29: 369-389.

Fishbein, M., and Middlestadt, S. E. (1989). Using the theory of reasoned action as a framework for understanding and changing AIDSrelated behaviors. In Mayo, M., Albee, G., and Schneider, F. (eds.), Primary Prevention of AIDS: Psychological Approaches. Sage, Newbury Park, CA, pp. 93-110.

Fisher, J. D. (1988). Possible effects of reference group-based social influence on AIDS-risk behavior and AIDS prevention. Am. Psychol. 43: 914-920.

Fox, G. (1977). Sex-role attitudes as predictors of contraceptive use among unmarried university students. Sex Roles 3: 265-283.

Galambos, N., Peterson, A., Richards, M., and Gitelson, I. B. (1985). The attitudes toward women scale for adolescents (AWSA): A study of reliability and validity. Sex Roles 13: 343-354.

Garner, A., Sterk, H. M., and Adams, S. (1998). Narrative analysis of sexual etiquette in teenage magazines. J. Commun. 48: 59-78. 
Gow, J. (1995). Reconsidering gender roles on MTV: Depictions in the most popular music videos on the early 1990s. Commun. Rep. 9: 151-161.

Gerbner, G., Gross, L., Morgan, M., and Signorielli, N. (1994). Growing up with television: The cultivation perspective. In Bryant, J., and Zillman, D. (eds.), Media Effects: Advances in Theory and Research. Erlbaum, Hillsdale, NJ, pp. 17-41.

Greenberg, B. S. (1993). Race differences in television and movie behaviors. In Greenberg, B. S., Brown, J. D., and Buerkel-Rothfuss, N. L. (eds.), Media, Sex, and the Adolescent. Hampton Press, Creskill, NJ, pp. $145-152$.

Greenberg, B. S., Brown, J. D., and Buerkel-Rothfuss, N. L. (1993). Media, Sex, and the Adolescent. Hampton Press, Creskill, NJ.

Greenberg, B. S., and Busselle, R. W. (1996). Soap operas and sexual activity: A decade later. J. Commun. 46: 153-160.

Greenberg, B. S., Linsangan, R., and Soderman, A. (1993). Adolescents' reactions to television sex. In Greenberg, B. S., Brown, J. D., and Buerkel-Rothfuss, N. L. (eds.), Media, Sex, and the Adolescent. Hampton Press, Creskill, NJ, pp. 177-224.

Greeson, L. E., and Williams, R. A. (1986). Social implications of music videos for youth: An analysis of the content and effects of MTV. Youth Soc. 18: 177-189.

Haferkamp, C. J. (1999). Beliefs about relationships in relation to television viewing, soap opera viewing, and self-monitoring. Curr. Psychol. 18: 193-204.

Harrison, K. (1997). Does interpersonal attraction to thin media personalities promote eating disorders? J. Broadcasting Electron. Media 41: 478-500.

Higgins, E. T., and King, G. A. (1981). Accessibility of social constructs: Information-processing consequences of individual and contextual variability. In Cantor, N., and Kihlstrom, J. F. (eds.), Personality, Cognition, and Social Interaction. Erlbaum, Hillsdale, NJ, pp. 69-122.

Huston, A. C., Wartella, E., and Donnerstein, E. (1998). Measuring the Effects of Sexual Content in the Media. Kaiser Family Foundation, Menlo Park, CA

Jo, E., and Berkowitz, L. (1994). A priming effect analysis on media influences: An update. In Bryant, J., and Zillman, D. (eds.), Media Effects: Advances in Theory and Research. Erlbaum, Hillsdale, NJ, pp. 43-60.

Kalof, L. (1999). The effects of gender and music video imagery on sexual attitudes. J. Soc. Psychol. 139: 378-385.

Kunkel, D., Cope, K. M., and Biely, E. (1999). Sexual messages on television: Comparing findings from 3 studies. J. Sex Res. 36: 230-236.

Kunkel, D., Cope, K. M., and Colvin, C. (1996). Sexual Messages on Family Hour Television: Content and Context. Oakland \& Menlo Park, CA: Children Now and Kaiser Family Foundation.

Levy, M. R. (1983). Conceptualizing and measuring aspects of audience 'activity.' Journalism Q. 60: 109-115.

Levy, M. R., and Windahl, S. (1984). Audience activity and gratifications: A conceptual clarification and exploration. Commun. Res. 11: 51-78.

Lowry, D. T., and Towles, D. E. (1989). Soap opera portrayals of sex, contraception, and sexually transmitted diseases. J. Commun. 39: 76-83.

MacCorquodale, P. (1984). Gender roles and premarital contraception. J. Marr. Fam. 46: 57-63.

Metzler, C. W., Noell, J., and Biglan, A. (1992). The validation of a construct of high-risk sexual behavior in heterosexual adolescents. J. Adolesc. Res. 7: 233-249.

Oliver, M. B., and Hyde, J. S. (1993). Gender differences in sexuality: A meta-analysis. Psychol. Bull. 114: 29-51.

Olson, B. (1994). Sex and the soaps: A comparative content analysis of health issues. Journalism Q. 71: 840-850.

Page, R., Hammermeister, J. J., and Scanlan, A. (2000). Everybody's not doing it: Misperceptions of college students' sexual activity. Am. J. Health Behav. 24: 387-394.
Perse, E. M. (1986). Soap opera viewing patterns of college students and cultivation. J. Broadcasting Electron. Media 30: 175-193.

Pistella, C. L. Y., and Bonati, F. A. (1998). Communication about sexual behavior among adolescent women, their family, and peers. Fam. Soc.: J. Contemp. Hum. Serv. March-April, 206-211.

Pleck, J. H., Sonenstein, F. L., and Ku, L. C. (1993). Masculinity ideology: Its impact on adolescent males' heterosexual relationships. J. Soc. Issues 49: 11-29.

Potter, W. J. (1986). Perceived reality and the cultivation hypothesis. J. Broadcasting Electron. Media 30: 159-174.

Rubin, A. M. (1984). Ritualized and instrumental television viewing. J. Commun. 34: 67-77.

Rubin, A. M. (1994). Media uses and effects: A uses-and-gratifications perspective. In Bryant, J., and Zillman, D. (eds.), Media Effects: Advances in Theory and Research. Erlbaum, Hillsdale, NJ, pp. $417-436$

Rubin, A. M., and Perse, E. M. (1987). Audience activity and television news gratifications. Commun. Res. 14: 58-84.

Rudman, L. A., and Borgida, E. (1995). The afterglow of construct accessibility: The behavioral consequences of priming men to view women as sexual objects. J Exp. Soc. Psychol. 31: 493-517.

Sapolsky, B. S., and Tabarlet, J. O. (1991). Sex in primetime television: 1979 versus 1989. J. Broadcasting Electron. Media 35: 505-516.

Schwartz, P., and Rutter, V. (1998). The Gender of Sexuality. Pine Forge Press, Thousand Oaks, CA.

Scott-Jones, D., and White, A. (1990). Correlates of sexual activity in early adolescence. J. Early Adolesc. 10: 221-238.

Sherman, B. L., and Dominick, J. R. (1986). Violence and sex in music videos: TV and rock ' $n$ ' roll. J. Commun. 36: 79-93.

Strasburger, V. (1995). Adolescents and the Media: Medical and Psychological Impact. Sage, Thousand Oaks, CA.

Strouse, J. S., and Buerkel-Rothfuss, N. L. (1987). Media exposure and the sexual attitudes and behaviors of college students. J. Sex Educ. Ther. 13: 43-51.

Strouse, J. S., Buerkel-Rothfuss, N. L., and Long, E. C. (1995). Gender and family as moderators of the relationship between music video exposure and adolescent sexual permissiveness. Adolescence 30: $505-521$.

Strouse, J. S., Goodwin, M. P., and Roscoe, B. (1994). Correlates of attitudes toward sexual harrassment among early adolescents. Sex Roles 31: 559-577.

Sun, S.-W., and Lull, J. (1986). The adolescent audience for music videos and why they watch. J. Commun. 36: 115-125.

Tolman, D. L., and Higgins, T. (1996). How being a good girl can be bad for girls. In Maglin, N. B., and Perry, D. (eds.), Good Girls/Bad Girls: Women, Sex, Violence and Power in the 1990s. Rutgers University Press, New Brunswick, NJ, pp. 205-225.

Walsh-Childers, K., and Brown, J. D. (1993). Adolescents' acceptance of sex-role stereotypes and television viewing. In Greenberg, B. S., Brown, J. D., and Buerkel-Rothfuss, N. L. (eds.), Media, Sex, and the Adolescent. Hampton Press, Creskill, NJ, pp. 117-133.

Ward, L. M. (1995). Talking about sex: Common themes about sexuality in the prime-time television programs children and adolescents view most. J. Youth Adolesc. 24: 595-615.

Ward, L. M., and Rivadeneyra, R. (1999). Contributions of entertainment television to adolescents' sexual attitudes and expectations: The role of viewing amount versus viewer involvement. J. Sex Res. 36: 237-249.

Ward, L., and Wyatt, G. (1994). The effects of childhood sexual messages on African-American and White women's adolescent sexual behavior. Psychol. Women Q. 18: 183-201.

Whitaker, D., and Miller, K. (2000). Parent-adolescent discussions about sex and condoms: Impact on peer influences of sexual risk behavior. J. Adolesc. Res. 15: 251-273.

Winslow, R. W., Franzini, L. R., and Hwang, J. (1992). Perceived peer norms, casual sex, and AIDS risk prevention. J. Appl. Soc. Psychol. 22: $1809-1827$. 